\title{
The use of Aedes aegypti larvae attractants to enhance the effectiveness of larvicides
}

\author{
Paula V. Gonzalez ${ }^{1}$ • Laura Harburguer ${ }^{1}$ • Paola A. González-Audino ${ }^{1}$ • \\ Héctor M. Masuh ${ }^{1}$
}

Received: 2 November 2015 / Accepted: 17 February 2016

(C) Springer-Verlag Berlin Heidelberg 2016

\begin{abstract}
Aedes aegypti (L.) is an important dengue, chikungunya, and yellow fever vector. Immature stages of this species inhabit human-made containers placed in residential landscapes, and the application of larvicides inside containers that cannot be eliminated is still considered a priority in control programs. Larvicidal efficacy is influenced by several factors, including the formulation used, the water quality, and the susceptibility of larvae, among others. If an attractant can be incorporated into a slow-release larvicide formulation, it will be feasible to direct the larvae into the source of insecticide and thereby improving its efficacy. We studied the influence of 1-octen-3ol and 3-methylphenol on the rate of $A e$. aegypti larvae mortality using the larvicides Bacillus thuringiensis var. israelensis (Bti), temephos, and spinosad. These chemicals were combined with the larvicides mixed with agar during the bioassays. Mortality was registered every $10 \mathrm{~min}$, and a lethal time $50\left(\mathrm{LT}_{50}\right)$ was calculated. The inclusion of the Ae. aegypti larvae attractants with the larvicides into a solid agar matrix improved their efficiency obtaining a strong and marked reduction in the $\mathrm{LT}_{50}$ compared with the use of larvicides alone.
\end{abstract}

Keywords Mosquito $\cdot$ Larvae $\cdot$ Attractant $\cdot$ Insecticide

Héctor M. Masuh

hmasuh@citedef.gob.ar

1 Centro de Investigaciones de Plagas e Insecticidas (CONICET-CITEDEF), Juan Bautista de La Salle 4397,

B1603ALO Villa Martelli, Provincia de Buenos Aires, Argentina

\section{Introduction}

Aedes aegypti (L.) is a container-breeding mosquito that commonly inhabits urban and suburban areas throughout the world. They are diurnally active, highly anthropophilic, and a potential vector of the dengue, yellow fever, and chikungunya viruses to humans. Globally, there are 50 to 100 million dengue cases resulting in thousands of deaths annually (WHO 2006a). Ae. aegypti control is mainly directed against immature stages (education, source reduction, and larviciding) to reduce the production of new adult mosquitoes, with some efforts devoted to controlling adult mosquitoes using spatial sprays of adulticides during dengue outbreaks (Gratz 1999; Pilger et al. 2010).

Developmental stages of Ae. aegypti can be found in artificial containers and natural sites close to human dwellings (Barrera 1996; Scott et al. 2000). In such situations, the likely breeding sites can be treated with larvicides and oviposition repellents as components of the integrated approach to mosquito population management (Hwang et al. 1980; Curtis and Hill 1988; Xue et al. 2001; Tikar et al. 2014). However, not all breeding sites can be totally eliminated or made mosquitoproof, and it is difficult to involve all members in the community in a sustained clean-up campaign. In addition, neither adulticides nor larvicides are completely effective against Ae. aegypti. The development of novel, effective methods for the control of dengue vectors are therefore urgently needed, with particular emphasis on methods that are environmentally friendly, cost-effective, and suitable for integration into community-based control programs (Service 1992; Swaddiwudhipong et al. 1992; Chunsuttiwat and Wasakarawa 1994).

The behavior of the immature stages of holometabolous insects is mainly led by short-range orientation to food sources, feeding behavior, and defensive responses. The 
sensory requirements of the larvae are more limited than those of the adults, and this is reflected in the smaller number of integumental sensilla and the lower capabilities of certain larva sense organs (Xia 2008). Mosquito larvae manifest a number of behavioral responses towards different kinds of stimuli such as light, food, color, etc. (Merritt et al. 1992). Responses towards food sources are believed to be largely driven by olfactory chemosensory stimuli (Merritt et al. 1992) and have been studied in many mosquito species. Aedes vexans larvae, when placed in a dish with incompletely separated compartments, congregated in the compartments that contained pellets of fishmeal or wheat flour (Aly 1985). In addition, Culex quinquefasciatus larvae became concentrated and showed positive chemotaxis in regions of water containing casein hydrolysate or the amino acids phenylalanine, aspartic acid, and proline (Barber and Burnton 1983). Also, mosquito larvae accumulate in regions where there is food as the result of orthokinetic responses to soluble constituents diffusing from the food with the involvement of their olfactory systems (Merritt et al. 1992).

The aquatic larval habitats inherently represent a confined and, therefore, a more easily targeted site for mosquito control strategies. Although a lot of efforts have been put into developing novel repellents and attractants for adult mosquitoes with low toxicity to non-target organisms, very few similar studies have been done on larvae. The available larvicides focus on high efficiency of killing and low toxicity towards other organisms. Furthermore, if coupled with larval attractants, larvicides may have an improved chance to kill their larvae targets.

Since larvicides for Ae.aegypti control are mainly used in drinking water, not all the known compounds can be used. World Health Organization (WHO) allows only temephos, Bacillus thuringiensis var. israelensis (Bti), spinosad, and some IGRs such as methoprene, pyriproxyfen, and novaluron (WHO 2007a, b, 2008, 2009, 2010). In addition, some synthetic pyrethroids are very effective but care must be taken when used as larvicides due to their toxicity to aquatic nontarget organisms (WHO 2006b). Besides, the use of larvicides is limited by issues such as the emergence of resistance, already known for temephos in almost Latin-American countries including Argentina (Majori et al. 1986; Coosemans and Carnevale 1995; Braga et al. 2004; Ocampo et al. 2011). The efficacy of larvicides relies on several factors including the formulation, water quality, and the susceptibility of the targeted larvae (Walker and Lynch 2007; Harburguer et al. 2009). If a slow-release formulation could be modified by adding a strong attractant, it would be possible to increase the larval density proximate to insecticides and thereby greatly enhance their effectiveness.

In this study, we combine the study of chemical attractants of well-known Ae. aegypti larvae combined with larvicides in order to increase their selectivity and efficiency. The aim of this work is to contribute to innovation in control strategies by using more selective modes of action, lower risk to non-target organisms, and lower environmental impact tools.

\section{Materials and methods}

\section{Insecticides}

A commercial formulation of $B t i$ was used Larvicidal Mosquito Dunks ${ }^{\circledR}$ by Summit Chemical Co., $10 \% p / p$, 7000 international toxic units/mg. Technical-grade spinosad was provided by Dow AgroSciences. Technical-grade temephos (97.6 \%) was provided by Supelco Analytical Bellefonte, PA, USA.

\section{Chemicals}

1-Octen-3-ol (98\%) and 3-methylphenol (>97\%) were purchased from Sigma-Aldrich (St. Louis, USA). Acetone (>99.8\%) was purchased from Merck (Germany). Ethanol absolute $(99.5 \%)$ was purchased from Sintorgan S.A. (Argentina). Agar-agar was purchased from Parafarm ${ }^{\circledR}$ (Saporiti, Argentina).

\section{Biological material}

A susceptible strain of Ae. aegypti (CIPEIN) was used. This strain, originated from the Rockefeller strain in Venezuela, had been kept in the laboratory since 1996, reared at 25 $\pm 2{ }^{\circ} \mathrm{C}$ under L:D 12:12 $\mathrm{h}$ according to previous reports from the laboratory (Seccacini et al. 2006). For this study, 100 late third-instar or early fourth-instar larvae were used. These larvae were washed with dechlorinated water and kept without food for $2 \mathrm{~h}$ at $27^{\circ} \mathrm{C}$.

\section{Combination of insecticide plus attractant}

Odorant stock solutions were prepared by dissolving a specific amount of the odorants in a preheated $5 \%$ agar-agar solution. The concentrations used in this study were $10^{-03}$ and $0.1 \mathrm{mg} / \mathrm{ml}$ of 1-octen-3-ol and 3-methylphenol. These compounds and concentrations were chosen as they evoke attractant responses in Ae. aegypti larvae (Gonzalez et al. 2015).

For larvicidal bioassays, $2 \mathrm{~g}$ of the Bti commercial briquette were weighted out. Spinosad $(40 \mathrm{mg} / \mathrm{ml})$ and temephos $(1 \mathrm{mg} / \mathrm{ml})$ solutions were prepared in acetone and ethanol, respectively. Whatman filter papers no. 2 (4.25 $\mathrm{cm}$ diameter) were impregnated with $0.5 \mathrm{ml}$ of the stock solution of each larvicide. Acetone and ethanol were allowed to evaporate for $24 \mathrm{~h}$. 


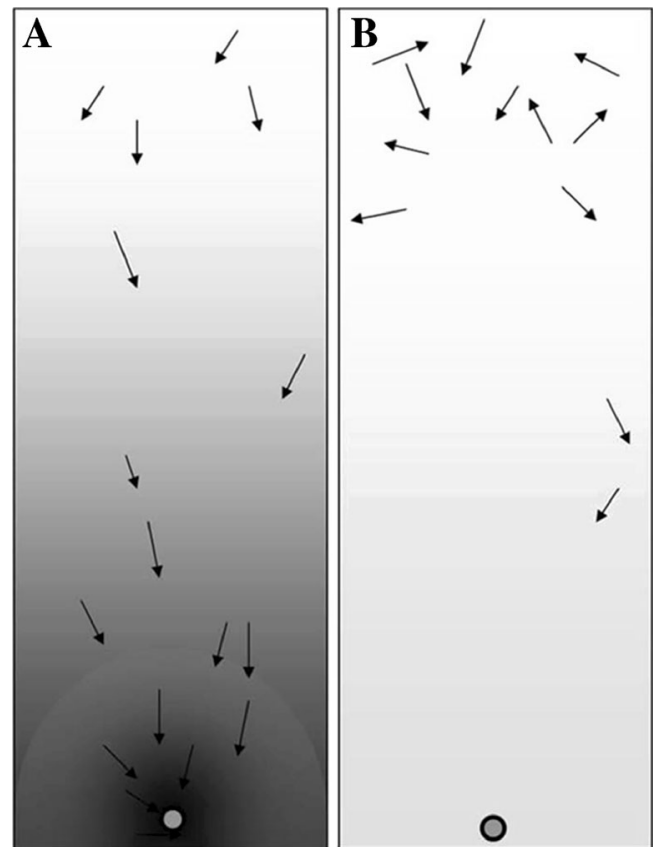

Fig. 1 Schematic diagram showing the setup of the larvicidal bioassay. a Larvicide plus attractant. b Larvicide alone. The arrows represent mosquito larvae

\section{Larvicidal bioassay}

The larvicidal activity of the selected insecticides in combination with the larval attractants was evaluated on Ae. aegypti larvae according to the following method. Plastic containers $(27 \times 37 \times 9 \mathrm{~cm})$ with 31 of dechlorinated water maintained at $27{ }^{\circ} \mathrm{C}$ were placed next to each other under the same light conditions. Both the insecticide (either filter papers impregnated or briquette) and the odorant (in agar) to be tested were bound, with insect pins (Bioquip $\mathrm{N}^{\circ} 6$ ), at one end of the container and maintained completely submerged. A concentration gradient of the odorant in the water was allowed to be formed for $30 \mathrm{~min}$. One hundred late third-instar and/or early fourthinstar Ae. aegypti larvae, carefully washed, were released at the opposite side of the odorant plus insecticide (Fig. 1). Larvae mortality was recorded every $10 \mathrm{~min}$ for $6 \mathrm{~h}$ starting $20 \mathrm{~min}$ after the larvae were incorporated to the container. The trial included a control with only insecticide and no odorant, and a negative control (with odorant but without insecticide). The time required for $50 \%$ of the population in the container to die $\left(\mathrm{LT}_{50}\right)$ was calculated by the Litchfield and Wilcoxon (1949) method.

\section{Statistical analysis}

The median lethal time $\left(\mathrm{LT}_{50}\right)$ with $95 \%$ confidence interval (CI) was obtained by means of PoloPlus 2.0 software (LeOra Software Company, Petaluma, CA) and was expressed in minutes.

\section{Results}

Table 1 shows the results of $\mathrm{LT}_{50}$ for $B t i$ in the presence of different concentrations of the odorant 3-methylphenol. With increasing concentrations of 3-methylphenol, we found that the time required for $50 \%$ mortality decreases from 100 to $88.9 \mathrm{~min}$; however, this difference was not significant. The best performance was obtained for Bti plus $0.1 \mathrm{mg} / \mathrm{ml} \mathrm{3-}$ methylphenol. The confidence intervals at $95 \%$ indicate that $\mathrm{LT}_{50}$ for the control (153 min), using Bti alone, was significantly different from $\mathrm{LT}_{50}$ in all the concentrations.

Table 2 shows the results of $\mathrm{LT}_{50}$ of Bti combined with different concentrations of 1-octen-3ol. Again, the larvicide that was combined with the odorant resulted more effective than when used alone. Both concentrations tested showed statistically different efficacy than the control. A slightly better larvicidal effect was obtained with $10^{-03} \mathrm{mg} / \mathrm{ml}$ of 1 -octen-3ol (76.1 $\mathrm{min}$ ) than for $0.1 \mathrm{mg} / \mathrm{ml}(80.5 \mathrm{~min})$; however, this difference was not statistically different. Those concentrations of attractants that were the most effective in reducing the $\mathrm{LT}_{50}$ were selected to test their efficacy with the other two insecticides.

Table 3 shows the results of $\mathrm{LT}_{50}$ of spinosad in the presence of both odorants. As the results found for Bti, when the larvicide was combined with the odorants, it resulted more effective than using the larvicide alone. No significant
Table $1 \mathrm{LT}_{50}$ of Ae. aegypti larvae for Bti plus 3methylphenol at different concentrations

\begin{tabular}{llll}
\hline Treatment & $n$ & Slope (SE) & $\mathrm{LT}_{50}(95 \% \mathrm{CI})[\mathrm{min}]$ \\
\hline Control (odorant) & 4 & - & $>360^{\mathrm{a}}$ \\
Control (Bti) & 4 & $6.015(0.185)$ & $153.1 \mathrm{a}(145.1-163.3)$ \\
$10^{-03} \mathrm{mg} / \mathrm{ml}$ 3-methylphenol + Bti & 4 & $5.818(0.150)$ & $100.0 \mathrm{~b}(94.9-105.4)$ \\
$0.1 \mathrm{mg} / \mathrm{ml}$ 3-methylphenol + Bti & 4 & $6.295(0.153)$ & $88.9 \mathrm{~b}(81.5-96.3)$ \\
\hline
\end{tabular}

Numbers followed by the same letter are not significantly different from each other based on non-overlap of confidence limits. $P<0.05$

$C I$ confidence interval

${ }^{\text {a }}$ No mortality was recorded in the untreated control at the end of the assay $(6 \mathrm{~h})$ 
Table $2 \mathrm{LT}_{50}$ of Ae. aegypti larvae for Bti plus 1-octen-3ol at different concentrations

\begin{tabular}{llll}
\hline Treatment & $n$ & Slope (SE) & LT $_{50}(95 \%$ CI) [min] \\
\hline Control (odorant) & 3 & - & $>360^{\mathrm{a}}$ \\
Control (Bti) & 3 & $4.999(0.172)$ & $115.5 \mathrm{a}(107.1-126.3)$ \\
$10^{-03} \mathrm{mg} / \mathrm{ml} \mathrm{1-octen-3ol+Bti}$ & 3 & $5.147(0.161)$ & $76.1 \mathrm{~b}(64.3-87.5)$ \\
$0.1 \mathrm{mg} / \mathrm{ml} \mathrm{1-octen-3ol}+B t i$ & 3 & $5.740(0.179)$ & $80.5 \mathrm{~b}(71.4-89.7)$ \\
\hline
\end{tabular}

Numbers followed by the same letter are not significantly different from each other based on non-overlap of confidence limits. $P<0.05$

$C I$ confidence interval

${ }^{a}$ No mortality was recorded in the untreated control at the end of the assay $(6 \mathrm{~h})$ differences were found between the odorant used, and $\mathrm{LT}_{50}$ values were higher than when we used Bti.

Finally, when the larvicide temephos was combined with the odorants, the $\mathrm{LT}_{50}$ were significantly lower than when used alone (Table 4). Furthermore, $\mathrm{LT}_{50}$ with 1-octen-3ol (122.4 min) was significantly lower than with 3methylphenol (146.6 min). $\mathrm{LT}_{50}$ values for the combination of temephos plus the odorant were similar to those for spinosad but higher than the ones for Bti.

\section{Discussion}

In this work, we studied the lethal time of larval mortality 50 $\left(\mathrm{LT}_{50}\right)$ by combining known larval attractants with larvicides of conventional use in order to determine whether the attractant effect would enhance the larvicidal effect.

When Bti was used in combination with the attractants 1octen-3ol or 3-methylphenol, a significant reduction in the $\mathrm{LT}_{50}$ was observed with respect to the control of Bti alone. The best performances were achieved for concentrations of $10^{-03}$ and $0.1 \mathrm{mg} / \mathrm{ml}$ of 1 -octen-3ol and 3-methylphenol, respectively.

$B t i$ is a spore-forming bacterium that produces a proteinaceous incrustation in a crystalliferous body during sporulation. The crystal consists of a least four protein protoxins. Upon digestion by an insect having a sufficiently high midgut $\mathrm{pH}$, the dissolved protoxins are enzymatically converted to the toxins (Federici and Wu 1994; Patil et al. 2012). If the larva is a mosquito or other susceptible dipteran species, the toxins attach to receptors in the midgut membrane and initiate a process ending in cell lysis. An individual insect dies when a sufficient amount of toxin is ingested and activated (Skovmand et al. 1998). Ultimately, the mortality in a population of susceptible larvae is dependent upon the quality and quantity of toxin ingested. Due to this fact, by combining $B t i$ with a larval attractant, the time to run into the larvicide is reduced and the intake accelerated, producing an overall reduction in the $\mathrm{LT}_{50}$.

Results of our work show that when spinosad was used in combination with the larval attractants, also a significant reduction in the $\mathrm{LT}_{50}$ was observed. Spinosad is highly active by both contact and ingestion to numerous pests in the orders Lepidoptera, Diptera, Thysanoptera, Coleoptera, Orthoptera, Hymenoptera, and others (Bret et al. 1997; Kovendan et al. 2012). It affects the insect nervous system at unique sites on the nicotinic acetylcholine and gamma-aminobutyric acid (GABA) receptors (Hertlein et al. 2010). Field studies suggest that rates of spinosad used nowadays will need to be increased in response to habitats with very high levels of liquid or solid sewage such as cisterns (Cetin et al. 2005) or street drains (Sadanandane et al. 2009). This observed reduction in spinosad's larvicidal efficacy could be due to adsorption, soil
Table $3 \mathrm{LT}_{50}$ of Ae. aegypti larvae for spinosad plus 3methylphenol and 1-octen-3ol at 0.1 and $10^{-03} \mathrm{mg} / \mathrm{ml}$, respectively

\begin{tabular}{llll}
\hline Treatment & $n$ & Slope (SE) & LT $_{50}(95 \%$ CI) [min] \\
\hline Control (odorant) & 3 & - & $>360^{\mathrm{a}}$ \\
Control (spinosad) & 3 & $4.955(0.255)$ & $224.5 \mathrm{a}(212.3-240.1)$ \\
$0.1 \mathrm{mg} / \mathrm{ml} \mathrm{3-methylphenol} \mathrm{+} \mathrm{spinosad}$ & 3 & $3.693(0.115)$ & $120.5 \mathrm{~b}(117.3-123.9)$ \\
$10^{-03} \mathrm{mg} / \mathrm{ml} \mathrm{1-octen-3ol+spinosad}$ & 3 & $3.308(0.108)$ & $126.6 \mathrm{~b}(122.8-130.7)$ \\
\hline
\end{tabular}

Numbers followed by the same letter are not significantly different from each other based on non-overlap of confidence limits. $P<0.05$

CI confidence interval

${ }^{a}$ No mortality was recorded in the untreated control at the end of the assay $(6 \mathrm{~h})$ 
Table $4 \mathrm{LT}_{50}$ of Ae. aegypti larvae for temephos plus 3 methylphenol and 1-octen-3ol at 0.1 and $10^{-03} \mathrm{mg} / \mathrm{ml}$, respectively

\begin{tabular}{llll}
\hline Treatment & $n$ & Slope (SE) & LT $_{50}$ (95 \% CI) [min] \\
\hline Control (odorant) & 4 & - & $>360^{\mathrm{a}}$ \\
Control (temephos) & 4 & $5.666(0.137)$ & $251.9 \mathrm{a}(245.5-259.0)$ \\
$0.1 \mathrm{mg} / \mathrm{ml}$ 3-methylphenol + temephos & 4 & $5.357(0.096)$ & $146.6 \mathrm{~b}(142.4-150.8)$ \\
$10^{-03} \mathrm{mg} / \mathrm{ml}$ 1-octen-3ol + temephos & 4 & $5.828(0.105)$ & $122.4 \mathrm{c}(117.6-127.2)$ \\
\hline
\end{tabular}

Numbers followed by the same letter are not significantly different from each other based on non-overlap of confidence limits. $P<0.05$

$C I$ confidence interval

${ }^{a}$ No mortality was recorded in the untreated control at the end of the assay $(6 \mathrm{~h})$ microbial degradation, decreased ingestion by larvae, or allalthough adsorption is the likelier explanation given the much longer half-lives involved in microbial degradation (Saunders and Bret 1997). Incorporating a larval attractant to a formulation of spinosad, as proposed in our work, could improve its effectiveness in habitats with high levels of sewage since ingestion by mosquito larvae would occur before the larvicide is adsorbed and its efficacy reduced.

Also, when temephos was used in combination with larval attractants, a significant reduction in the $\mathrm{LT}_{50}$ was observed. Temephos is a soluble organophosphate (OP) that has been widely used for mosquito larvae control for up to 50 years. It has a neurotoxic mode of action which inhibits acetylcholinesterase and is still widely used in mosquito control programs (Ang and Satwant 2001; Tikar et al. 2009).

The use of push-pull tactics fits within the emerging view that vector control strategies should be expanded beyond insecticide-dependent methods (Cook et al. 2006). Combining the mechanisms of attraction and repellency has the potential to result in a synergistic effect (Thomas et al. 2012). By 'pushing' mosquitoes away from certain places using repellents, one could stimulate their movement towards other places where they are 'pulled' into traps baited with attractive cues (Menger et al. 2014). From the results obtained in this study, it gives rise to the possibility of applying the push-pull tactic for controlling mosquito larvae, expelling them from their shelters with a repellent, and directing them into traps with attractants combined with a lethal agent. Although it is known that Ae. aegypti larvae inhabits confined containers, some evidence has been found that they also can be located in shallow water bodies (Chadee et al. 1998) and therefore this kind of tactics could be applied in such cases. The results obtained in this work for Ae. aegypti could be extended to mosquitoes that live in large water bodies, such as Anopheles or Culex, considering that larvae attractants for C. pipiens quinquefasciatus and Anopheles gambiae have already been identified (Barber and Burnton 1983; Xia 2008).

Behavioral and toxicological evidence presented here shows that larval attractants decrease the lethal times of the three larvicides tested. The best results were obtained with $B t i$, due possibly to the fact that we used a commercial briquette with inert ingredients that could increase its bioavailability unlike with temephos and spinosad wherein technical grade was used.

The use of a slow-release formulation with the addition of a strong attraction may increase larval density near the insecticide area and thereby enhancing its effectiveness and skipping or reducing problems of lack of persistence associated with the effect of UV radiation, temperature, and microbial degradation.

Acknowledgments This study received financial support by the ANPCyT of Argentina (PICT 2008-797). LH, PGA, and HM are members of the CONICET. PG has a grant from CONICET.

\section{References}

Aly C (1985) Feeding rate of larval Aedes vexans stimulated by food substances. J Am Mosq Control Assoc 1:506-510

Ang KT, Satwant S (2001) Epidemiology and new initiatives in the prevention and control of dengue in Malaysia. Dengue Bull 25:7-14

Barber JT, Burnton CP (1983) Chemotaxis of Culex pipiens quinquefasciatus larvae (Diptera: Culicidae) in response to amino acids. J Med Entomol 20:641-643

Barrera R (1996) Competition and resistance to starvation in larvae of container-inhabiting Aedes mosquitoes. Ecol Entomol 21(2):117127

Braga IA, Lima JBP, Soares SS, Valle D (2004) Aedes aegypti resistance to temephos during 2001 in several municipalities in the states of Rio de Janeiro, Sergipe and Alagoass, Brazil. Mem Inst Oswaldo Cruz 99:199-203

Bret BL, Larson LL, Schoonover JR, Sparks TC, Thompson GD (1997) Biological properties of spinosad. Down Earth 52(1):6-13

Cetin H, Yanikoglu A, Cilek JE (2005) Evaluation of the naturallyderived insecticide spinosad against Culex pipiens L.(Diptera: Culicidae) larvae in septic tank water in Antalya, Turkey. J Vector Ecol 30(1):151

Chadee DD, Ward RA, Novak RJ (1998) Natural habitats of Aedes aegypti in the Caribbean - a review. J Am Mosq Control 14(1):5-11

Chunsuttiwat S, Wasakarawa S (1994) Dengue vector control in Thailand: development towards environmental protection. Gaoxiong Yi Xue Ke Xue Za Zhi 10:122-123

Cook SM, Khan ZR, Pickett JA (2006) The use of push-pull strategies in integrated pest management. Annu Rev Entomol 52(1):375 
Coosemans M, Carnevale P (1995) Malaria vector control: a critical review on chemical methods and insecticides. Ann Soc Belg Med Trop 75:13-31

Curtis CF, Hill N (1988) Comparison of methods of repelling mosquitoes. Entomol Exp Appl 49(1-2):175-179

Federici, BA, Wu D (1994) Synergism of insecticidal activity of Bacillus thuringiensis. In:R. Akhurst (ed.). Proc 2nd Canberra Bacillus thuringiensis meeting

Gonzalez PV, Gonzlez Audino PA, Masuh HM (2015) Behavioral response of Aedes aegypti (Diptera: Culicidae) larvae to synthetic and natural attractants and repellents. J Med Entomol. doi:10. 1093/jme/tjv136

Gratz NG (1999) Emerging and resurging vector-borne diseases. Annu Rev Entomol 44(1):51-75

Harburguer LV, Seccacini E, Masuh H, Gonzalez Audino P, Zerba E, Licastro S (2009) Thermal behaviour and biological activity against Aedes aegypti (Diptera: Culicidae) of permethrin and pyriproxyfen in a smoke-generating formulation. Pest Manag Sci 65:1208-1214

Hertlein MB, Mavrotas C, Jousseaume C, Lysandrou M, Thompson GD, Jany W, Ritchie SA (2010) A review of spinosad as a natural product for larval mosquito control. J Am Mosq Control 26(1):67-87

Hwang YS, Kramer WL, Mulla MS (1980) Oviposition attractants and repellents of mosquitoes. Isolation and identification of oviposition repellents for Culex mosquitoes. J Chem Ecol 6:71-80

Kovendan K, Murugan K, Kumar AN, Vincent S, Hwang JS (2012) Bioefficacy of larvicidal and pupicidal properties of Carica papaya (Caricaceae) leaf extract and bacterial insecticide, spinosad, against chikungunya vector, Aedes aegypti (Diptera: Culicidae). Parasitol Res 110(2):669-678

Litchfield JA, Wilcoxon F (1949) A simplified method of evaluating dose-effect experiments. J Pharmacol Exp Ther 96(2):99-113

Majori G, Sabatinelli G, Villani F, Petrarca V (1986) Studies on insecticide susceptibility of Anopheles gambiae and Culex quinquefasciatus in the area of Ouagadougou, Burkina Faso (west Africa). J Am Mosq Control 2:305-309

Menger DJ, Otieno B, De Rijk M, Mukabana WR, Van Loon JJ, Takken W (2014) A push-pull system to reduce house entry of malaria mosquitoes. Malar J 13:119

Merritt RW, Dadd RH, Walker ED (1992) Feeding behavior, natural food, and nutritional relationships of larval mosquitoes. Annu Rev Entomol 37:349-376

Ocampo CB, Salazar-Terreros MJ, Mina NJ, Mc Allister S, Brogdon W (2011) Insecticide resistance status of Aedes aegypti in 10 localities in Colombia. Acta Trop 118(1):37-44

Patil CD, Patil SV, Salunke BK, Salunkhe RB (2012) Insecticidal potency of bacterial species Bacillus thuringiensis SV2 and Serratia nematodiphila SV6 against larvae of mosquito species Aedes aegypti, Anopheles stephensi, and Culex quinquefasciatus. Parasitol Res 110(5):1841-1847

Pilger D, De Maesschalckm M, Horstick O, San Martin JL (2010) Dengue outbreak response: documented effective interventions and evidence gaps. insectTropIKA.net. http://journal.tropika.net/ pdf/tropika/v1n1/a02v1n1.pdf

Sadanandane C, Boopathi Doss PS, Jambulingam P, Zaim M (2009) Efficacy of two formulations of the bioinsecticide spinosad against Culex quinquefasciatus in India. J Am Mosq Control 25(1):66-73

Saunders DG, Bret BL (1997) Fate of spinosad in the environment. Down Earth 52(1):14-20

Scott T, Morrison A, Lorenz L, Clark G, Strickman D, Kittayapong P (2000) Longitudinal studies of Aedes agypti (Diptera: Culicidae) in Thailand and Puerto Rico: population dynamics. J Med Entomol 32: $77-88$
Seccacini E, Masuh H, Licastro S, Zerba E (2006) Laboratory and scaled up evaluation of cis-permethrin applied as a new ultra low volume formulation against Aedes aegypti (Diptera: Culicidae). Acta Trop 97:1-4

Service MW (1992) Importance of ecology in Aedes aegypti control. Southeast Asian J Trop Med Public Health 23:681-690

Skovmand O, Thiery I, Benzon GL, Sinegre G, Monteny N, Becker N (1998) Potency of products based on Bacillus thuringiensis var. israelensis: interlaboratory variations. J Am Mosq Control 14(3): 298-304

Swaddiwudhipong W, Lerdlukanavonge P, Khumklam P, Koonchote S, Nguntra P, Chaovakiratipong C (1992) A survey of knowledge, attitude and practice of the prevention of dengue hemorrhagic fever in an urban community of Thailand. Southeast Asian J Trop Med Public Health 23:207-211

Thomas MB, Godfray HC, Read AF, Van Den Berg H, Tabashnik BE, van Lenteren JC, Wage JK, Takken W (2012) Lessons from agriculture for the sustainable management of malaria vectors. PLoS Med 9(7), e1001262

Tikar SN, Kumar A, Prasad GBKS, Prakash S (2009) Temephos-induced resistance in Aedes aegypti and its cross-resistance studies to certain insecticides from India. Parasitol Res 105(1):57-63

Tikar SN, Yadav R, Mendki MJ, Rao AN, Sukumaran D, Parashar BD (2014) Oviposition deterrent activity of three mosquito repellents diethyl phenyl acetamide (DEPA), diethyl $\mathrm{m}$ toluamide (DEET), and diethyl benzamide (DEB) on Aedes aegypti, Aedes albopictus, and Culex quinquefasciatus. Parasitol Res 113(1):101-106

Walker K, Lynch M (2007) Contributions of Anopheles larval control to malaria suppression in tropical Africa: review of achievements and potential. Med Vet Entomol 21:2-21

World Health Organization (WHO) (2006a) Report of the scientific working group meeting on dengue. TDR/SWG/08, Geneva, Switzerland

World Health Organization (WHO) (2006b) Pesticides and their application: for the control of vectors and pests of public health importance. 6th ed, Geneva, Switzerland

World Health Organization (WHO) (2007a) Methoprene in drinking-water: use for vector control in drinking-water sources and containers - background document for development of WHO guidelines for drinking-water quality WHO/SDE/NSM/07.01/11

World Health Organization (WHO) (2007b) Novaluron in drinking-water: use for vector control in drinking-water sources and containers - background document for development of WHO guidelines for drinking-water quality WHO/SDE/WSH/07.01/11

World Health Organization (WHO) (2008) Pyriproxyfen in drinking-water: use for vector control in drinking-water sources and containers - background document for development of WHO guidelines for drinking-water quality WHO/HSE/AMR/08.03/9

World Health Organization (WHO) (2009) Temephos in drinking-water: use for vector control in drinking-water sources and containersbackground document for development of WHO guidelines for drinking-water quality $\mathrm{WHO} / \mathrm{HSE} / \mathrm{WSH} / 09.01 / 1$

World Health Organization (WHO) (2010) Spinosad DT in drinking-water: use for vector control in drinking-water sources and containers - background document for development of WHO guidelines for drinking-water quality WHO/HSE/WSH/10.01/12

Xia Y (2008) Molecular and cellular studies of mosquito odorant receptors and olfactory-driven larval behavior, $\mathrm{PhD}$ Thesis, Vanderbilt University, Nashville, Tennessee, USA

Xue RD, Barnard DR, Ali A (2001) Laboratory and field evaluation of insect repellents as oviposition deterrents against the mosquito Aedes albopictus. Med Vet Entomol 15(2):126-131 